\title{
EFECTO DEL ASOCIO TOMATE-MAÍZ PARA EL CONTROL DE (Alternaria solani) y Phytophthora infestans EN EL VALLE DE ZAPOTITAN*
}

\author{
Jaime E.Ayala**; Rodolfo Godinez *** y Maritza de Doñan***
}

\begin{abstract}
RESUMEN
Con el objetivo de determinar el efecto que la planta de maiz pudiera ejercer como barrera física para disminuir la incidencia de tizón temprano y tizón tardío, se efectuó un experimento en la Estación Experimental San Andrés, ubicada a $450 \mathrm{msnm}$ en El Salvador. Se utilizó el diseño estadístico de bloques completos al azar con un arreglo de parcelas divididas con cuatro repeticiones, las parcelas grandes fueron el tiempo de asocio del maíz (20, 10 y cero días antes del trasplante del tomate) y las parcelas pequeñas el distanciamiento de las barreras del maíz (un surco de maíz cada 3 o 5 surcos de tomate). Se evaluó la severidad de ambos patógenos y el número y altura de plantas infestadas, de tomate, número de frutos y rendimiento. Se realizó análisis de presupuesto parcial. Se disminuyó la incidencia de A. solani y $P$. infestans. La interacción de maíz sembrado 20 días antes del trasplante y cada tres surcos de tomate presentó menor severidad de ambos patógenos, menor número de plantas infestadas, la mayor altura en plantas de tomate y el mayor número de frutos (rendimiento de 22 $687 \mathrm{~kg} / \mathrm{ha}$ ). El análisis del presupuesto parcial mostró un beneficio neto, en el tratamiento de maíz 20 días antes del trasplante y cada tres surcos de tomate de 8,500.00 colones.
\end{abstract}

\begin{abstract}
In the horticultural zone in Zapotitán, the tomato crop is affected by several diseases, but more heavily by those of fungal origin, among which stabd out the early blight $(A$. solani) and late blight ( $P$. infestans). The trial was conducted at the San Andres Experiment Station, located at 450 masl average temperature of $23,8^{\circ} \mathrm{C}$, a relative humidity of $36 \%$ and the soil $\mathrm{pH}$ of 6.3 to determine the effect of the corn plant as a living barrier. A split-plot, complete randomized block experimental design with four replications was used. Nine treatments were evaluated, divided in area of $3496 \mathrm{~m}^{2}$. were the large plts were the intercropping times and the useful area. The parameters evaluated were: severity of both pathogens and number of infested plants, tomato's plant height, number of fruits and yield. A partial budget analysis was conducted. The tomato crop responded favorably to the corn intercropping, lowering the incidence of A.solani and P. infestans. the corn intercropping planted 20 days before trasplanting and every three rows of tomato showed a lower severity of both pathogens, lower number of infested plants and registered the largest height of the tomato plants, which was ovrious be cause of the low severity when compared to the other treatments. The same treatment produced the largest number of fruits, yielding 22.687 $\mathrm{kg} / \mathrm{ha}$, being superior to the remaining treatments which fluctuated around $19.000 \mathrm{~kg} / \mathrm{ha}$. The analysis of the partial budget showed anet benefit, with the corn treatment 20 days before trasplanting and every three rows of tomato, of $\phi 8.500$ which is higher to the benefits produced with the other treatments.
\end{abstract}

\section{INTRODUCCION}

En la zona hortícola de Zapotitán, el cultivo de tomate se ve afectado por la incidencia de diversas enfermedades, siendo de mayor importancia las de origen fungoso, entre las que destacan el tizón temprano Alternaria solani y tizón tardío Phytophthora infestans, ambas enfermedades atacan principalmente en la época lluviosa, así como también en la época seca causando notorias pérdidas en la producción (Christ 1987).

Las enfermedades causadas por Phytophthora infestans y Alternaria solani han sido objeto de numerosos trabajos de investigación realizados por CENTA, centrando el tipo de control en aplicaciones químicas, que a la fecha han creado o causado resistencia por parte del patógeno. El control de estos patógenos utilizando prácticas culturales, en este caso, barreras vivas para evitar la disminución de esporas, es valedera al buscar nuevas alternativas que acompañadas a las aplicaciones químicas, pueden brindar mejores resultados en el aspecto económico y ambiental. Se conocen de asocios de maíz-tomate-rábano y otros multicultivos, para evaluar rendimiento y aprovechamiento de espacio, pero no evaluados dentro de un contexto de protección vegetal.

La disminución de A. solani y P. infestans, puede ser realizada por varios medios, principalmante el viento (Mesiaen y Lafon 1968). El hongo se aloja en restos de

\footnotetext{
* Trabajo presentado a la XXXVII Reunión Anual del PCCMCA. Panamá. 1991.

** Técnico del Departamento Horticultura, CENTA/MAG. El Salvador.

*** Técnicos auxiliares, Departamento Horticultura.
} 
plantas enfermas pudiendo infestar la siguiente cosecha, las esporas sueltas sobreviven en la superficie del suelo. Pueden producirse, además, esporulaciones del hongo seco y requiere solamente un período corto de alta humedad relativa, para germinar o penetrar. Los conidios se desprenden con facilidad y son diseminadas por las corrientes de aire, sus esporas están presentes en el aire y en el polvo en todas partes (Alexopulos 1976). Ambas enfermedades también se diseminan por medio de la semilla, pues fácilmente se contamina durante el proceso de extracción (Cásseres 1980). La enfermedad tizón temprano puede presentarse en cualquier época del año, pero es más importante en la época lluviosa CENTA (1985).

Ambas enfermedades podr ían controlarse con fungicidas como clorotalonil captafol, mancozeb, maneb, repitiendo las aspersiones de acuerdo a la incidencia de las enfermedades. En época lluviosa se recomienda un intervalo de cuatro días en cada aplicación (Rosales y Pérez 1985, Villarreal 1982).

El maíz H-56 es un híbrido doble con rendimientos de $90 \mathrm{qq} / \mathrm{mz}$, un ciclo vegetativo de 110 días, altura de planta de $276 \mathrm{~cm}$ y altura de mazorca de $150 \mathrm{~cm}$ tolerante al acame y al achaparramiento, con tallo vigoroso y con 14-16 hileras de maíz por mazorca, el color del grano es blanco, (CENTA, 1985). N30).

Los objetivos específicos fueron:

A. Determinar el efecto de la época de siembra; del asocio maíz-tomate para disminuir la diseminación del tizón tardío.

B. Determinar el ordenamiento espacial de la siembra del maíz en el cultivo de tomate para contrarrestar la diseminación de $P$. infestans y A solani.

\section{MATERIALES Y MÉTODOS}

El ensayo se realizó en la Estación Experimental San Andrés 2, a una altura de $450 \mathrm{msnm}$ con temperatura promedio de $23,82 \mathrm{C}$, humedad relativa del $76 \%$ y precipitación anual de $1701 \mathrm{~mm}$, suelo de topografía plana, textura franco arenosa, suelo con vocación agrícola y con $\mathrm{pH}$ de 6,3 .

El diseño estadístico utilizado fue de parcelas divididas, con distribución de bloques al azar con cuatro repeticiones. Los factores de variación fueron: Factor A: tiempo de asocio (parcelas grandes): $\mathrm{A}_{1}=$ maíz sembrado 20 días antes del trasplante; $A_{2}=$ maíz sembrado 10 DA T; $A_{3}=$ maíz sembrado al momento del trasplante. Factor B: distanciamiento (parcelas chicas); $\mathrm{B}_{1}$ $=1$ surco de maíz por cada 3 de tomate; $\mathrm{B}_{2}=1$ surco de maíz por cada 5 de tomate, $\mathrm{B}_{3}=$ tomate solo. $\mathrm{El}$ área de la unidad experimental fue de $96 \mathrm{~m}^{2}$, con 16 surcos de 5 $\mathrm{m}$ de largo $\mathrm{c} / \mathrm{u}$, con un área de $24 \mathrm{~m}^{2}$. Un total de 36 parcelas, con un área de $3456 \mathrm{~m}^{2}$. Las variables evaluadas fueron: 1: severidad del daño de ambos Tizones: número de plantas y frutos infestados, porcentaje de daño, (Escala de Christ, 1987). 2: altura de plantas de tomate; 3: rendimiento.

La variedad de tomate utilizada fue UC-82. La preparación del terreno y labores agronómicas se hicieron de acuerdo a las recomendaciones técnicas ya conocidas. Se aplicaron insecticidas cada 8 días (metamidofos, Deltametrina alternados, y metomil). Las aplicaciones de fungicidas se realizaron cada 8 días y en ocasiones cada 10 días y consistieron en usar Maneb y Mancozeb alternados. El distanciamiento de siembra utilizado fue de 1,20m x 0,40 m la variedad de máiz utilizada fue H-56, la siembra se realizó en el tiempo estipulado, se utilizó Etoprofos $10 \% \mathrm{G}(25 \mathrm{lb} / \mathrm{mz})$ al suelo. Se fertilizó con fórmula 16-20-0 (4,0 qq/ mz) y con sulfato de amonio (4,0 qq/ma). Se hicieron dos aplicaciones de metamidofos para control de Spodoptera frugiperda.

\section{RESULTADOS Y DISCUSIÓN}

\section{Infestación de Alternaria solani}

En la Figura 1, se presentan los promedios de severidad de A. solani durante el ciclo del cultivo.

Hubo diferencias significativas para el efecto de los tratamientos. El menor porcentaje $(0,98)$ se obtuvo con el maíz sembrado 20 días antes del trasplante cada tres surcos de tomate. El resto de tratamientos mostró infestación que varió de 1,12 a 5 por ciento, obteniéndose el mayor porcentaje de infestación con el testigo.

En lo que respecta al número de plantas dañadas, el distanciamiento, un surco de maíz por cada tres de tomate mostró diferencias significativas, obteniéndose con dicho distanciamiento un promedio de 12,08 plantas dañadas, que resulta inferior al promedio de 17,25 y 21,08 registrados para el distanciamiento un surco de maíz por cada cinco de tomate y tomate solo respectivamente. 


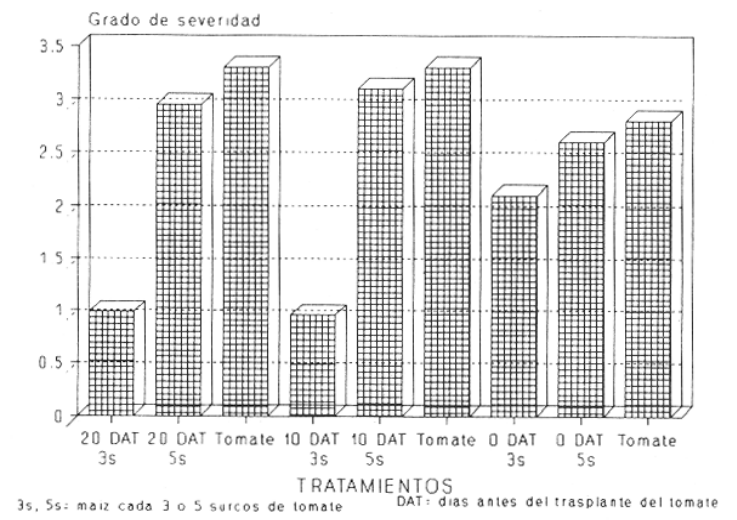

Figura 1. Promedio de severidad de $\underline{A}$. solini en tomate intercalado con maíz. Estación Experimental San Andrés. 1990.

\section{Infestación de Phytophthora infestans.}

En la Figura 2, se presentan los promedios de severidad de $\underline{\mathrm{P}}$. infestans durante el ciclo del cultivo.

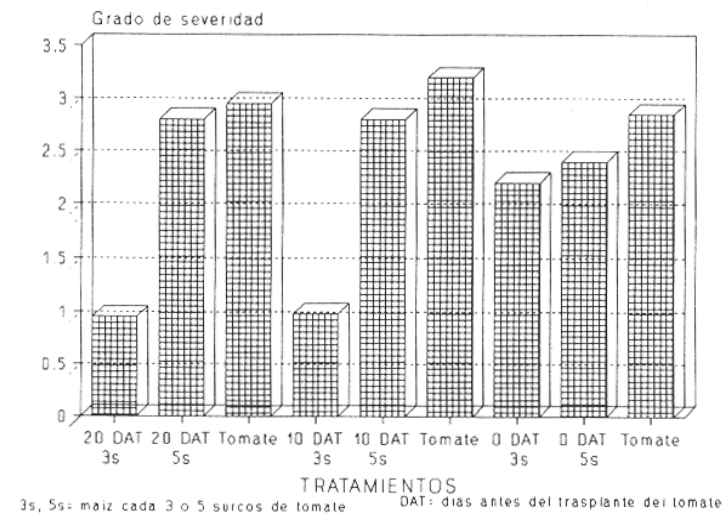

Figura 2. Promedio de severidad de $\underline{\mathbf{P}}$. infestans en tomate intercalado con maíz. Estación Experimental San Andrés. 1990.

El tratamiento maíz sembrado 20 días antes del trasplante y cada tres surcos de tomate, proporcionó mejor protección al cultivo; hubo infestación del 1,03\%, diferente significativamentes con los demás tratamientos evaluados, que variaron de 1,48 a 4,29\% de infestación.

El tiempo de asocio con respecto al número de plantas con daño de $P$. infestans muestra que el menor daño correspondió a maíz sembrado 20 y 10 días del trasplante con valores de 17,17 y 15,50 respectivamente y el mayor número de plantas dañadas, se obtuvo con la siembra de maíz al momento del transplante, con un valor de 21,75 plantas. En lo que respecta a los distanciamientos, el menor número de plantas dañadas correspondió a un surco de maíz por tres de tomate con un valor de 13,50, el mayor número de plantas dañadas se obtuvo al utilizar tomate solo y un surco de maíz por cada cinco de tomate.

\section{Rendimiento}

Hubo diferencias significativas para el rendimiento de tomate comercial. Para el tiempo de asocio, la siembra de 20 y 10 días antes del trasplante proporcionó un rendimiento de $21985.33 \mathrm{~kg} / \mathrm{ha}$, siendo superior al rendimiento que resulta de sembrar maíz al momento del trasplante (19 916.66 kg/ha).

El rendimiento obtenido al utilizar un surco de maíz por cada tres surcos de tomate fue de $22,687.5 \mathrm{~kg} / \mathrm{ha}$, que resultó ser superior significativamente al rendimiento obtenido con tomate solo y un surco de maíz por cada cinco de tomate $(19916 \mathrm{~kg} / \mathrm{ha})$.

De acuerdo a los resultados obtenidos, el rendimiento y considerando que todos los tratamientos estuvieron sometidos a similar manejo agronómico, es notoria la protección fitosanitaria ejercida por la barrera de maíz al cultivo del tomate.

\section{CONCLUSIONES}

1. El cultivo de tomate respondió favorablemente, al ser utilizado maíz, como barrera viva, disminuyendo la incidencia y diseminación de $A$. solani y $P$. infestans en el cultivo de tomate.

2. El distanciamiento del que se obtuvieron mejores resultados en protección al tomate, fue el de un surco de maíz por cada tres surcos de tomate.

3. El tratamiento de maíz sembrado 20 días antes del trasplante y cada tres surcos de tomate, fue la interacción que presentó menor severidad de $A$. solani y P. infestans.

4. El mayor rendimiento de tomate se obtuvo con la interacción de maíz sembrado 20 días antes del trasplante y distribuidos cada tres surcos de tomate, destacando que el tratamiento de maíz sembrado 10 días antes del trasplante y cada tres surcos de tomate tuvo similar rendimiento. 
Estos resultados muestran en términos generales, que para una producción rentable de tomate, es necesario la combinación de prácticas culturales, en este caso barreras vivas, con el uso de plaguicidas en forma racionada para protección del cultivo. Se hace notar que el costo de la producción no se ve alterado por el uso de la barrera viva, por el contrario, al bajar el número de aplicaciones existe una reducción en el costo que implica el uso de fungicidas.

Es importante el beneficio ecológico que significa la combinación de estas técnicas, ya que al permitir la reducción en el número de aplicaciones, se retrasa el desarrollo de resistencia de la plaga y se reducir ía el impacto de los plaguicidas sobre la salud humana y el ambiente.

\section{LITERATURA CITADA}

ALEXOPULOS, C. J. 1976. Introducción a la Micología, Trad. por Digihio 2a. ed. Buenos Aires, Argentina. Eudeba. p. 423.

CASSERES, E. 1980. Producción de Hortalizas. 3 ed. Lima, Perú. IICA. pp. 94-95.

CENTRO DE TECNOLOGIA AGRICOLA, 1985. Documento técnico sobre aspectos agropecuarios. San Andrés. El Salvador. CENTA, Manual Técnico $\mathrm{N}^{\circ} 3$. pp. 18-19.

CHRIST, B. J. 1987. Reaction of potato cultivars to Early Bligth Biological and Cultural Tests. 2:17.

GUDIEL, M. 1987. Manual Agrícola Superb. Ged. Guatemala, Superb. pp. 202-205 ( $\left.\mathrm{N}^{\circ} 6.1085-1987\right)$

MESIAEN, C. M.; LARFON, R. 1968. Enfermedades de las hortalizas. Barcelona, España. pp. 144

ROSALES, G.M.; PEREZ, J.; CUELLAR, A 1985. Guía técnica de hortalizas. S.e. ISTA. p. 144.

VILLARREAL, R. 1982. Tomates. Trad. por Gilberto Camacho. San José, Costa Rica. IICA. pp. 81-82. 